\title{
Electrochemistry of organic and bioactive compounds
}

\author{
Tomáš Navrátil $^{1}$ [ · Miroslav Fojta ${ }^{2}$
}

Received: 18 February 2019 / Accepted: 19 February 2019 / Published online: 25 February 2019

(C) Springer-Verlag GmbH Austria, part of Springer Nature 2019

It is our pleasure to introduce this special issue of the journal Monatshefte für Chemie-Chemical Monthly, as the fourth one devoted to the international conference the Modern Electrochemical Methods (MEM) series. The previous special issues were devoted to the conference MEM XXXIV (organized in 2014), MEM XXXV (2015), and MEM XXXVI (2016). The current special issue is composed of articles based on the selected lectures presented at the international conference MEM XXXVIII, held from May 21 to May 25, 2018, in Jetřichovice, the Czech Republic.

All the above-mentioned conferences have belonged to the traditional series of conferences started in 1980 in Mezni Louka, Czech Republic. Conferences of the MEM series have been organized annually since then (with only one exception in 1989). We have registered different places in the Czech Republic where these conferences have been organized. Nevertheless, the "Bohemian Switzerland" region in the west-northern part of the Czech Republic, and particularly a small village Jetřichovice near Děčín, has become the most popular and, consequently, the most traditional place for organizing the MEM conferences (since 1999, twice the MEM events were held at different places).

Let us to express our great pleasure that this conference series has developed in a traditional meeting opportunity for young as well as top senior electrochemists (mostly - but not only-focused on electroanalysis) from the Czech Republic, Slovakia, as well as from many other European (Poland, Russia, Slovenia, Germany, UK, and Romania) as well as non-European countries (e.g., USA, Republic of South Africa, India, Iran, or Egypt). An increasing number of top specialists from various countries, participating in particular conference years, signalize the increasing reputation of the MEM conferences.

Tomáš Navrátil

Tomas.Navratil@jh-inst.cas.cz

1 Czech Academy of Sciences, J. Heyrovský Institute of Physical Chemistry, Dolejškova 3, 18223 Prague 8, Czech Republic

2 Czech Academy of Sciences, Institute of Biophysics, Kralovopolská 135, 61265 Brno, Czech Republic
Similarly as in the previous years, in 2018 , the presented lectures were devoted to progress in electrochemistry of organic and bioactive compounds, to mechanistic studies of electrochemical processes involving reducible or oxidizable organic moieties, to development of novel materials for construction of working electrodes, design of measuring configurations and electrochemical (bio)sensors, as well as to analytical techniques designed for the determination of biologically active compounds (such as toxic substances or drugs) in various matrices. Attention was also paid to electrochemical analysis of biopolymers, their labeling with redox active species, and prospective utilization in novel diagnostic approaches employing electrochemical detection platforms. Moreover, some contributions dealt with the utilization of some other analytical techniques, e.g., mass spectrometry, HPLC, and their combination with electrochemical techniques.

This issue contains 1 review, 15 original papers, and 2 short communications related to lectures presented at the MEM XXXVIII, which we can consider as a representative selection of contributions covering the above-mentioned topics. Each article was reviewed by at least two independent international reviewers and not all submitted articles have finally been accepted for publication.

As Editors of this special issue, we would like to express our gratitude to the Managing Editor, Christian Hametner, and to the Editor-in-Chief of the journal, Peter Gärtner, for their assistance and cooperation, and the staff of the Publisher, Springer Vienna, for their contribution to the special issue release. We are very glad that we have been enabled to realize the series of special issues, which brought information about our conferences and provided the selection of results presented there to the readers of the journal Monatshefte für Chemie-Chemical Monthly.

Once more, we thank all the authors for their great effort to contribute with the results of their research, and all referees for the valuable comments that helped to improve the quality of the manuscripts.

Enjoy reading! 